\title{
Knowledge Triangle Configurations at Three Swedish Universities
}

\author{
Eugenia Perez Vico ${ }^{\text {a;b }}$ \\ PhD Researcher, eugenia.perez_vico@fek.lu.se
}

Sylvia Schwaag Serger ${ }^{\text {c;a }}$

Director of International Strategy and Networks; and Adjunct Professor, sylvia.schwaagserger@vinnova.se

\section{Emily Wise ${ }^{\text {a }}$}

PhD Researcher, emily.wise@fek.lu.se

\author{
Mats Benner d;a \\ Professor, mats.benner@fek.lu.se
}

\author{
a Lund University, Box 708022007 Lund, Sweden. \\ ${ }^{b}$ Halmstad University, Kristian IV:s Vag 3, Halmstad, Sweden.
}

' Swedish Government Agency for Innovation (Vinnova), Se-101 58, Master Samuelsgatan 56, Stockholm, Sweden.

${ }^{d}$ Royal Institute of Technology (Kungliga Tekniska hogskolan, KTH). Address: Teknikringen 74D, Plan 5, SE-100 44, Stockholm, Sweden.

\begin{abstract}
$\mathrm{T}$ he concept of a knowledge triangle, i.e., the principle of strengthening the linkages between research, education and innovation, has emerged as a result of policymakers' expectations that universities assume a broader societal responsibility. Yet, little is known about how these tasks and their interactions are orchestrated at universities. We explore concept of how the knowledge triangle is manifested in the organisation and strategy of three different Swedish universities, and how these manifestations are shaped by the policy landscape. The article highlights the fact that although the knowledge triangle remains a priority, explicit national policies are lacking, with the responsibility of integration falling upon universities themselves. We observe great diversity in how

the principles of the knowledge triangle are orchestrated at the universities, e.g., through individuals' interpretations and attitudes, and through management strategies and incentive schemes. However, the three tasks have largely been handled separately, with weak coordination and generally limited ambition demonstrated by university management teams to forge new combinations of remits. At the individual and group levels, we observe weak task articulation, although some role models serve as inspiration. Tensions emerge as the responsibilities of operationalising the knowledge triangle falls on individuals who sometimes lack the appropriate mandate and resources. These findings raise questions for further research and implications for policy and university management.
\end{abstract}

\section{Keywords:}

knowledge triangle;

university management;

third mission;

societal collaboration;

research utilisation.
Citation: Perez Vico E., Schwaag Serger S., Wise E., Benner M. (2017) Knowledge Triangle Configurations at Three Swedish Universities. Foresight and STI Governance, vol. 11, no 2, pp. 68-82. DOI: 10.17323/25002597.2017.2.68.82 
$\mathrm{U}$ niversities are currently facing mounting policy expectations to assume broader social responsibility. As part of these expectations, policy institutions such as the European Commission and the Organisation for Economic Co-operation and Development (OECD) [European Commission, 2005; OECD, 2016a] have stressed the need to strengthen bilateral and trilateral ties between research, educational and innovation activity ${ }^{1}$, which they refer to as the Knowledge Triangle (KT).

Although the value of linking research, education and innovation is well known, strengthening these ties has often proven challenging [Maassen, Stensaker, 2011; Sjoer et al., 2016], revealing tensions between the different tasks and institutional levels [Pinheiro et al., 2014]. These tensions are to some extent inevitable, as the logic behind, and the incentive systems of, universities' tasks differ: education is place-bound and localised in its practices and reward systems; research is primarily valued according to its contributions to the international community, whereas innovation takes many different forms, from the tangible to the tacit.

Hence, the task of aligning the tasks and creating meaningful and rewarding ties between them is fraught with tension. Moreover, these difficulties can be assumed to play out differently at different types of universities. Universities are conditioned by factors such as their history, societal connectivity, operational focus and size [Clark, 1998; Stensaker, Benner, 2013]. This means their strategies and procedures for creating KT links can be expected to vary: teaching-intensive universities start out from their educational mission and align research and collaboration to that mission ("vocational drift"); research-intensive universities can be expected to use education and research as prolongations of their research strengths ("research drift"), whereas universities with strong social connections will mobilize their research and educational tasks to meet the specific needs and demands of their societal environment ("societal drift") [Martin, Etzkowitz, 2000]. These developmental paths can then be related to and compared with the ideals behind the KT, namely that that the three missions and tasks develop in parallel and without a hegemonic centre [Etzkowitz, Leydesdorff, 2000]. Given the significant policy interest in the KT, we see a need for a comprehensible understanding of real-world manifestations of the concept. Without such an understanding, resources may be misspent, and misguided pressure on academics and universities may emerge. Although significant policy attention has been directed towards the KT, scholarly interest has been lukewarm: only two studies explore the trilateral linkages of the KT at universities and both focus solely on the individual level [Holmén, Ljungberg, 2016; Sjoer et al., 2016]. The question of how institutions organise themselves for supporting KT principles therefore remains unexplored. Given the above, we set out to study how the principles of a KT are orchestrated ${ }^{2}$ at universities, guided by an exploratory research question: how are the principles of a KT manifested in the daily activity and strategies of different types of universities?

Swedish universities are of particular interest as an object of study. All Swedish universities are expected to cover the three corners of the KT within the same organisation and serve as "research institutes of society" that undertake a broad range of activities from basic research and education to contracted research and training. In addition, all educational programmes are included in the academic system, and all universities are included in the same unified system with equal remits. Furthermore, due to recent reforms, Swedish universities hold a large degree of organisational independence from the state: their rewards system, organisational matrixes and the structure of positions can be decided without governmental approval. This creates an opportunity to study a diversity of institutions within a unified system with similar expectations and opportunities to incorporate the principles of the KT.

\section{Analytical framework}

In line with [Markkula, 2013; Goosens, Sjoer, 2012], we regard the notion of a KT to be a conceptual and normative framework for understanding the creation and dissemination of knowledge as a multifactorial and systemic process that integrates education, research and innovation in a synergic way. The KT may be manifested in a rhetorical or political way, or through the build-up of new structures and processes at the micro (individual or research groups), meso (faculty, departmental or organisational) or macro (national or international policy) levels. The KT builds on the assumption that connections are productive and thus should be strengthened; our starting point is instead that such linkages will be temporary and conditional in the multi-purpose setting that is inherent to modern contemporary universities [Maassen, Stensaker, 2011].

To our knowledge, only two scientific studies explore the three-way linkages between the corners of the KT on the level of individual researchers and teachers: Holmén and Ljungberg [Holmén, Ljungberg, 2016] find reinforcing spill-overs between the tasks, with research being the task that contributes most, and Sjoer et al. [Sjoer et al., 2016] find that individual perceptions concerning the nature of a task is the main barrier impeding the creation of linkages. However, there are other relevant contributions covering twoway links that help us study manifestations of the KT.

\footnotetext{
${ }^{1}$ The third corner in the KT has been referred to as the "third mission" or innovation. Although largely overlapping, these concepts are not synonymous. In this paper, we frame the third corner of the knowledge triangle as innovation, since it is the most commonly used term in the KT concept. In the context of this paper, we define innovation as the exploitation of university-based knowledge outside of the academic realm.

${ }^{2}$ By orchestration we refer to the process of interpreting, adapting, arranging for, and implementing the principles of the knowledge triangle.
} 
Firstly, the link between research and education (the Humboldtian model) has traditionally received significant scholarly attention. Studies offer evidence of mutually nurturing links between research and teaching [Robertson, Bond, 2001; Holmén, Ljungberg, 2016], and task integration [Colbeck, 1998]. Concurrently, others show that the Humboldtian ideal is hard to live by. Geschwind and Broström [Geschwind, Broström, 2015] provide evidence of a division of labour between staff, and Marsh and Hattie [Marsh, Hattie, 2002] demonstrate that there is no significant relationship between research productivity and teaching quality. The debated causes of the divide include the concentration of research and the actual cost-effectiveness of the division of labour at the individual and institution levels [Clark, 1997; Maassen, Stensaker, 2011; Pinheiro et al., 2014].

Secondly, the link between research and innovation has been explored through studies of research collaboration [Sonnenwald, 2007; Bozeman, Boardman, 2014], university-industry interactions [Mansfield, 1998; Scott et al., 2001; Perkmann, Walsh, 2007; Perkmann et al., 2013], modes of knowledge production [Gibbons et al., 1994], the triple helix [Etzkowitz, Leydesdorff, 2000], the entrepreneurial university [Clark, 1998], the third mission of universities [Laredo, 2007; Pinheiro et al., 2015] and the position of universities in innovation systems [Fagerberg, Verspagen, 2009; Jacobsson, Perez Vico, 2010]. Many such studies describe the productive complementarity [Gulbrandsen, Smeby, 2005; D'Este, Perkmann, 2011; Wigren-Kristoferson et al., 2011; Fogelberg, Lundqvist, 2012], and underline the embeddedness of innovation in research [Etzkowitz, Leydesdorff, 2000; Pinheiro et al., 2015].

However, other studies raise concerns that short-term commercialisation comes at the expense of long-term research and undermines the efficiency of the division of labour between public and private research [Larsen, 2011], and even deteriorates academic virtues, such as scientific rigor, objectivity and independence [Slaughter et al., 2002]. Although empirical evidence predominantly shows a positive relationship between commercialisation and research performance, there are notable exceptions: Perkmann et al. [Perkmann et al., 2011] find no uniform relationship between industry involvement and faculty quality, and Buenstorf [Buenstorf, 2006] identifies occasional negative correlations between entrepreneurship and scientific performance as well as weak evidence of the benefits from entrepreneurship on scientific undertakings. Indeed, the direction of causality in the link between research and innovation remains unclear [Larsen, 2011].

Thirdly, and as to the education-innovation nexus, Holmén and Ljungberg [Holmén, Ljungberg, 2015] studied how experiences from innovation feed into education, and vice versa, albeit to a lesser extent. Other studies indicate that conflicting logic hampers this particular form of interaction: Maassen and Stensaker [Maassen, Stensaker, 2011] argue that the standardisation of academic programmes within Europe stands in contrast to ambitions of renewal and creativity, which could lead to a divergence of the two.

This review reveals that linkages include both task combinations and mutually reinforcing spill-overs. However, it also reveals tensions, trade-offs and misalignments between formal and informal institutions in the pursuit of creating KT combinations. In exploring the nature of manifestations of the KT, the concept of institutions as formulated by North [North, 1990] and Scott [Scott, 2014] therefore appears useful as it helps us identify and structure observations. Institutions are the rules created by humans that condition interactions and thus the development of organisations. Institutions may be regulative [Scott, 2014], or as North [North, 1990] puts it, formal, and include laws, regulations or statutes. They may also be informal and include normative and cognitive dimensions, such as attitudes, beliefs and codes of conduct.

Against the above, we explore the manifestations of the KT as formal and informal institutions at universities at the micro (individual or research groups) and meso (faculty, departmental or organisational) levels, and contrast this against macro (national or international policy) level conditions. Formal institutions activity encompass the determination of policy priorities, strategy development, work routines, evaluation schemes and other tangible incentive frameworks. Informal institutions in this context include cognitive interpretations of and attitudes towards the KT held by individuals representing different levels (micro, meso or macro), as well as their culture and behavioural norms.

\section{Method}

We conduct our analysis through a two-step mixed method approach. Firstly, we search for insight into the conditions of the current Swedish policy landscape concerning the KT using scholarly articles and policy reports from public and private research funding organisations, public agencies, non-profit organisations and interest groups. Secondly, we conduct case studies on three universities selected for their representativeness of the Swedish university population in term of size and type (i.e., comprehensive, specialised or regional). The selected universities are Lund University, Chalmers University and Malmö University. Lund University is one of Sweden's large, comprehensive universities with long-standing traditions and experience in all three areas of the KT, but a clear budgetary focus on research. Chalmers represents a specialised university with ambitious management traditions and extensive industrial collaboration; it is as research-oriented as Lund University, but places a stronger emphasis on innovation. Malmö University is one of Sweden's newer regional universities, where its engagement with the local community (including the city and industry) has been central to the formulation of research and 
Table 1. List of interviewees and their position

\begin{tabular}{|l|l|}
\hline \multicolumn{2}{|c|}{ Item } \\
\hline \multicolumn{2}{|c|}{ Losition } \\
\hline L1 & Pro Vice-Chancellor (for external engagement) \\
\hline L2 & Pro Vice-Chancellor (for research and research infrastructure) \\
\hline L3 & Former Vice-Chancellor \\
\hline L4 & Professor (and Principal of the Helsingborg campus) \\
\hline L5 & Professor \\
\hline C1 & Director of an Area of Advance \\
\hline C2 & Former Dean \\
\hline C3 & Professor A \\
\hline C4 & Vice principal A \\
\hline C5 & Vice principal B \\
\hline C6 & Vice principal C \\
\hline C7 & Professor B \\
\hline \multicolumn{2}{|l|}{} \\
\hline M1 & Dean and acting Deputy Vice-Chancellor \\
\hline M2 & Vice Chancellor \\
\hline M3 & Research coordinator \\
\hline M4 & Pro Vice-Chancellor \\
\hline Source: compiled by the authors. \\
\hline
\end{tabular}

educational programmes; it is also a heavily teaching-oriented university, with roughly two thirds of its turnover based in education.

The case studies mainly build on 17 interviews conducted between November 2015 and November 2016: five at Lund University, seven at Chalmers University and five at Malmö University (M1 was interviewed twice). Interviewees made up a representative sample of individuals with regard to research group, department, faculty and university management level (including Professor, Dean, Pro Vice Chancellor and Vice Chancellor levels), as well as to the universities' three tasks (see Table 1 for details on interviewee positions). The interviews are labelled in numerical order with the initial letter indicating the affiliation (e.g., L1 for the first interviewee at Lund University, C2 for the second interviewee at Chalmers and M3 for the third interviewee at Malmö University). In addition to the interviews, university policy documents and previous relevant studies were reviewed, and a relevant workshop was attended at Chalmers. This allowed us to triangulate our findings.

\section{The contextual policy setting}

Ever since the KT concept was introduced during the Sweden's EU presidency in 2009, Sweden has been at the forefront of related policy development [Benner, Sörlin, 2015]. The Swedish innovation agency Vinnova was commissioned by the government to operationalise the concept. Consequently, and in line with Vinnova's focus on innovation, the work with the concept has been narrowed down to improving the third mission. Thus, despite the overarching ambitions, Sweden lacks policies and instruments explicitly targeting the KT as a whole. However, there are several different policy groups that influence and relate to KT principles.

Firstly, as many other countries have done, Sweden has placed an increased emphasis on research excellence and concentration, and has therefore significantly increased universities' R\&D expenditures [Bienenstock et al., 2014]. The increase is chiefly channeled through the extensive use of funding instruments targeting excellent or strategic research areas and the environment, and through the partially performance-based, excellence-focused research funding scheme for block funding introduced by the government in 2009 [OECD, 2016b]. Consequently, an already strong prioritisation of research was reinforced [Pinheiro et al., 2014]. As advanced research and education is combined at one organisation, scientists can "liberate" themselves from teaching and transfer the task onto individuals with lower research ambitions or less success in gaining research funding [Carlsson et al., 2014; OECD 2016b].

Secondly, in line with international trends, the Swedish education system has undergone a dramatic increase in the volume of students and staff. Between 1985 and 2014, the number of full-time students in Sweden tripled [Eriksson, Heyman, 2014]. Even though public funding for teaching has grown, universities' funding for R\&D has increased significantly more [Swedish Higher Education Authority, 2015]. 
Thirdly, policy has encouraged a more systematic way of handling interactions between society and universities, and Swedish universities have actually started to embrace more systematic views, albeit evidence of causal links is lacking [Benner, Sörlin, 2015]. Indeed, the historically close societal interaction of Swedish universities has been unsystematic, and revolved around certain individuals, groups or communities. During the 1970s and 1980s, policymakers applied an institutional approach to societal interaction [Benner, Sörlin, 2015], setting up publicly funded programmes for interactions between universities and industry and "intermediaries" (e.g., offices and technology parks), which created a strong focus on the business sector in general and technology-based firms in particular.

Fourthly, a scattered research funding landscape together with the dispersed management and funding of research, education and innovation creates significant challenges from a KT perspective. Sweden's research funding system is characterised by a large number of funding organisations that mainly target selected research groups or individuals who obtain considerable resources and leverage [Jacob, 2015]. Changes in strategy occurred through specific R\&D programmes that thus yielded effects that are limited to specific research groups or academic disciplines [Benner, 2013]. In addition, since the late 1990s, Sweden has deregulated its academic career system: individual universities control the content of positions, including the relative shares of research and education, as well as funding sources. It is quite common to have permanent positions on the basis of external funding alone, with little or no teaching tied to them [Government of Sweden, 2016]. Consequently, much of the steering power lies in the hands of research funding agencies and research groups.

Fifthly, in line with international arguments that increased autonomy strengthens research performance and societal connectivity [Aghion et al., 2008], Swedish universities have seen their autonomy increase. Consequently, the expectations of task integration between the three components of the KT fall on universities themselves.

The Swedish university population includes three types of universities: comprehensive, specialised and regional universities. The three cases are selected as exemplars of these categories. An overview of key statistics is provided in Table 2 below, illustrating the differences in character of the three universities.

Lund University is one of Sweden's largest comprehensive universities with a long tradition of embeddedness in and interaction with its local communities. Although the university caters to a large number of students, it is strongly research-oriented as two-thirds of revenue come from research (see Table 2). Chalmers represents a specialised technical university with extensive and long-standing ties to related industries ${ }^{3}$. It has ambitious management traditions and is even more research-oriented than Lund, but with a stronger emphasis on innovation, as revealed by the relatively large share of collaborative public research funding (see Table 2). Malmö University is one of Sweden's newer regional ${ }^{4}$ universities, where the interaction with the local community (including the city authorities and industry), particularly with regard to articulating the demands of the local labour markets and the public sector's demand for skills in education and healthcare, has been central to the formulation of research and educational programmes. In contrast to Lund and Chalmers, Malmö is heavily teaching-oriented with roughly twothirds of its turnover in education (see Table 2).

In the following cases, the manifestations of the KT (in terms of informal and formal institutions) and observed challenges related to enabling KT ties are explored.

\section{Lund University}

Founded in 1666, Lund University (LU) is one of the oldest universities in Northern Europe and is ranked among the top 100 in the world ${ }^{5}$. LU is comprised of eight faculties ${ }^{6}$ located on campuses in Lund, Helsingborg and Malmö. LU is also home to a number of institutes, specialised research and innovation communities, and platforms for societal interaction. Two major facilities for materials research are currently under construction in Lund: the MAX IV Laboratory (a synchrotron radiation laboratory) and European Spallation Source (ESS, a European facility that will be home to the world's most powerful neutron source). These will be of decisive importance for materials and life sciences and for industrial development.

\section{Informal institutions}

At LU, the attitudes towards and the perceived value of pursuing each task of the KT vary — resulting in fragmentation or unbalanced linkages between the tasks.

\footnotetext{
${ }^{3}$ Other specialised universities in Sweden include agricultural and medical universities.

4 The term "regional" may be seen as a misnomer, as these universities recruit students and faculty as broadly - sometimes even more so - than comprehensive and specialised universities. The term "regional" indicates that they were founded as part of the regional mobilisation of resources after the industrial crises of the 1970s and 1990s.

${ }^{5}$ LU ranked 70th in QS ranking 2015/2016 and 90th in Times Higher Education World University ranking 2015/16.

${ }^{6}$ Engineering (LTH), Social Sciences, Humanities and Theology, Economics and Management, Medicine, (Natural) Science, Law, Fine and Performing Arts.
} 
Table 2. Key figures for the universities for the year 2014

\begin{tabular}{|c|c|c|c|}
\hline & Lund University & Chalmers University & Malmö University \\
\hline Year founded & 1666 & 1829 & 1998 \\
\hline Vision & $\begin{array}{l}\text { "to be a world-class university } \\
\text { that works to understand, } \\
\text { explain and improve our } \\
\text { world and the human } \\
\text { condition" }\end{array}$ & $\begin{array}{l}\text { "Chalmers for a sustainable } \\
\text { future" }\end{array}$ & $\begin{array}{l}\text { "A world where diversity, } \\
\text { knowledge and creativity is } \\
\text { transformed into action for } \\
\text { sustainable development" }\end{array}$ \\
\hline $\begin{array}{l}\text { Full time students (Undergraduate } \\
\text { and graduate students) }\end{array}$ & 27702 & 8926 & 12340 \\
\hline of which graduate students & 7146 & 3137 & 1438 \\
\hline Full-time faculty & 2997 & 1173 & 753 \\
\hline Professors & 708 & 201 & 77 \\
\hline Total revenue & $\begin{array}{l}7.5 \text { million SEK } \\
\text { (app. } 815,000 \text { EUR) }\end{array}$ & $\begin{array}{l}\text { 3,4 million SEK } \\
\text { (app. } 370,000 \text { EUR) }\end{array}$ & $\begin{array}{l}\text { 1,3 million SEK } \\
\text { (app. } 141,000 \text { EUR) }\end{array}$ \\
\hline $\begin{array}{l}\text { Research revenue as a share of total } \\
\text { revenue }(\%)\end{array}$ & 67.6 & 71.5 & 20.8 \\
\hline $\begin{array}{l}\text { Share of block funding (research and } \\
\text { education) (\%) }\end{array}$ & 56.2 & 48.4 & 75.7 \\
\hline $\begin{array}{l}\text { Share of public funding requiring } \\
\text { collaborative research with actors } \\
\text { outside academia }(2013)^{*}(\%)\end{array}$ & 9.7 & 22.5 & 14.8 \\
\hline \multicolumn{4}{|c|}{$\begin{array}{l}\text { * This includes funding from research funding organisations that require the participation of non-academic actors, such as from Vinnova or the } \\
\text { Knowledge Foundation. This data was provided directly by Vinnova and includes an elaboration by Vinnova on data from Statistics Sweden. }\end{array}$} \\
\hline
\end{tabular}

Central management at LU expresses the importance of the interplay between research, education and innovation - highlighting the university's vision "to be a world-class university that works to understand, explain and improve our world and the human condition" [Lund University, 2012]. At the same time, central management recognises that the faculties have no common interpretation or way of operationalising the KT.

"On an ideological level, the importance of the interplay is well understood and embedded in our strategy and employees' understanding. However, there is a long way to go before we realise our aim of having "complete" learning environments - with a well-functioning and balanced integration between research, education and innovation - across our faculties." (L1)

On an individual (or group) level, there is the general perception that research, education and innovation should be mutually reinforcing activities, as more "integration" can enhance the quality of each aspect. Yet the approach for linking the various elements differs broadly across LU's faculties and departments. For some faculties or disciplines with more direct and practical application to societal issues (e.g., engineering or social sciences), there is a more natural integration and responsiveness to society's needs. This has led to differing levels of competence and experience across the faculties in engaging with "outside" actors in the local/regional system and understanding and addressing their needs.

"Certain institutions are doing well to integrate research and education. These are often the same environments with well-defined strategies for interacting with society. In other cases, the three missions are developed in isolation of one another." (L2)

Many interviewees highlighted the importance of the culture and attitudes towards the different dimensions of the KT. The general perception is that efforts to integrate research, education and innovation are not recognised or rewarded.

"People don't get paid or recognised in any way for the third mission. Third mission activities are not seen as enhancing research and educational tasks, but rather taking time away from "core" tasks such as securing research financing." (L2)

" $L U$ is a rather traditional university - where a focus on research excellence has top priority. It is not easy to change a culture or an orientation towards research excellence. It's a long-term process, but also necessary to undertake to ensure that LU is well-positioned in the future." (L5)

\section{Formal institutions}

The central management at LU is comprised of a Vice Chancellor, a Deputy Vice Chancellor (responsible for education and international relations), a Pro Vice-Chancellor for Research, a Pro Vice-Chancellor 
for External Engagement, and a University Director. Each of the eight faculties has similar management structures, with a Dean and Vice-Deans who hold separate responsibilities for education and research (and, in some faculties, for innovation and/or international relations). The management of financial resources and personnel is highly decentralised.

The Strategic Development Plan for LU 2012-2016 sets out the overall goal of "the highest quality education, research, innovation and interaction with society" and outlines four strategies for achieving this goal (cross-boundary collaboration; internationalisation; quality enhancement; and leader, teacher, and employee excellence). These strategic ambitions are reflected in a number of recruited positions or support functions within the University's central administration, which were initiated or further developed under the leadership of the previous Vice-Chancellor.

"It is important to work proactively when developing collaborative relationships. The central administration can play an important role as a "development motor". [LU management] developed a number of structures, including LU Open ${ }^{7}$ and the Research and Innovation Council of Skåne, recruited personnel, and initiated activities to strengthen the interplay between research, education and innovation." (L3)

At the start of 2015, the current Vice-Chancellor and leadership team began to develop a new development strategy for LU and to undertake a number of changes to central support functions, including the delegation of responsibility for initiating and leading cross-boundary collaborative activities from the centre (through LU Open) to the faculties to ensure stronger embeddedness in core operations, that is, research and education [Lund University, 2015].

"All faculties should have their own platforms for developing relations with external actors, proactively initiating and following up on collaborative projects. It's understandable that the central level may be involved in initiating some platforms, such as cross-disciplinary ones, but these should be integrated and developed within the faculties and departments." (L4)

"There are examples of 'integrated knowledge triangles' within departments, but cross-disciplinary programmes or platforms are rare. The central administration has limited resources to support crossdisciplinary efforts, and those activities that have been initiated are not always viewed in a positive light. It seems to work better if one faculty has the lead - with the responsibility of involving other faculties. This ensures structures are stable and are perceived as 'core'." (L2)

The new strategy will play an important role in signalling LU's priorities for a stronger interplay between research, education and innovation (guiding the respective strategies at the faculty level). There is also a need for more concrete guidance on how the university will work operationally with the KT.

"The university leadership needs to provide a strategic direction, support structures and incentives, as well as visibility of good examples. [The integration of research, education and innovation] won't happen by itself." (L1)

"There seems to be a need for simplifying and clarifying the central support functions - clearly communicating a service offered to the recipient faculties and departments." (L4)

In addition, the central administration and faculty management see a need for changing the financing system to enable better integration between research, education and innovation. The necessary changes include the flexible use of existing budgetary allocations and financial support (or other incentives) for social and cross-disciplinary collaboration.

"It is difficult to finance the development of new educational programmes or research areas, as the financing system does not allow for the flexible use of budgetary allocations in research and education. A strengthened integration between research, education and innovation needs to be not only interesting, but also financially viable." (L2)

"There should be better incentives and financing for working with the third mission. It is important to have accessible financial support or seed money to start new things and weave in the third mission as part of educational and research activities." (L4)

"Collaboration across disciplines and with external actors [on education and research] can be strengthened through financing - or by making collaboration a requirement for accessing [certain] research financing." (L5)

\section{Observed challenges in realising knowledge triangle links}

There are two main tensions that challenge the orchestration of the KT at LU: the contradictions between the tasks, and the clash between the role of the central administration in relation to the faculties.

\footnotetext{
${ }^{7}$ LU Open was initiated in 2011 as a development unit (under the central administration's section for research, collaboration and innovation) and specialises in matching external stakeholders with researchers and students, and designing and executing projects with the objective of solving complex challenges.
} 
There are different ways of interpreting and implementing the KT across the faculties of LU. In general, most effort is focused on securing financing for and producing high quality research. Education is also a core priority, but may be viewed as a "second" priority after research. Innovation and social interaction is conducted on a very ad hoc basis (driven by individual values and passion, mostly based on free time). The result is a fragmentation between the various tasks and a lack of clarity about the benefits of strengthened integration.

The distribution of support functions and collaboration platforms between the central and faculty levels of management also causes problems. Thus, LU seems to be navigating between different integration models. One is the centralised model (including formal institutions such as LU Open, which actually initiate activities). The other is the current distributed model that anchors notions of integration among its faculties (which have very different structures, financing models, and attitudes towards both the importance and the operationalisation of the KT). This pluralism results in diverging views on how resources should be used and which activities provide the most value, as well as barriers to establishing cross-disciplinary collaboration for LU as a whole.

\section{Chalmers University of Technology}

Chalmers University of Technology (CUT) is a research-focused technical university situated in Gothenburg, Sweden's second largest city. Gothenburg has a rich industrial history and high R\&D intensity [Fogelberg, Lundquist, 2012]. CUT's industrial embeddedness is reflected in its position as the fifth university worldwide (2015) with the highest share of industrial co-publications according to the Leiden Ranking. CUT was founded as a vocational school in 1829 through a donation by an industrialist, but soon became state-owned. In 1994, the university was transformed into a private foundation with greater autonomy than other Swedish universities [Jacob et al., 2003]. Education (chiefly engineering) and research is conducted within 18 departments.

\section{Informal institutions}

At CUT, there are diverse cognitive understandings of what a KT includes. Consequently, attitudes towards its usefulness vary, as illustrated by two vice presidents:

"Through [...] a productive KT, we can create arenas for change [...] We have to train our organisation to enable this." [Holmberg, 2015]

"We do not work with the knowledge triangle [at CUT] because we do not think the concept fits with our integrated picture of the utilisation of research and education. The KT polarises the three tasks by placing them in corners." (C6)

A first aspect in which individual's understandings of the KT differ relates to the concept's novelty. According to some interviewees, it is nothing new:

"I feel that I truly work within the KT, but I seldom use the expression, maybe because it's self-evident." (C1) Others emphasise that the concept brings much needed attention to the third mission (C2, C3).

A second aspect concerns whether the realisation of the KT implies additional activities (C4), or the reworking of existing tasks:

"The relationship between education and innovation should not be about activities that 'season' education [...] but about revising entire educational programmes on the basis of universities' wider societal role." (C5)

A third aspect concerns diverse perceptions of the third mission. While some equate the third mission with innovation and focus on its link to research $(\mathrm{C} 4, \mathrm{C} 7)$, others emphasise wider societal responsibilities including sustainability (C5, [Holmberg, 2015]).

This diversity in the understandings adheres to the various cultures and values of individuals that both reflect CUT's industrial and entrepreneurial spirit, and traditional academic norms. CUT researchers with strong traditions of doing basic research in industrial contexts embrace the integration of academic and applied research cultures [Fogelberg, Lundquist, 2012]. Others mainly identify with academic norms and perceive integration as problematic [Jacob et al., 2003; Fogelberg, Lundquist, 2012]. An interviewee illustrates the latter view:

"Some researchers need to go upstairs in the ivory tower [...] and only come out every now and then to say things that amaze everybody [...] but if we only direct our research toward the needs and issues of specific actors [...] what about the future societal needs?" (C7)

The link between research and education is often combined in the same persons. However, further specialisation emerges partly due to the higher status of research that materialises through attitudes and norms $(\mathrm{C} 3, \mathrm{C} 5)$. The link between education and innovation are often driven by the commitment 
of teachers who use their networks to introduce practical elements (C3). The interest and motivation of students is also significant (C5).

\section{Formal institutions}

CUT applies a process-oriented management model, where vice presidents lead education, research and utilisation, respectively. Education has its own organisation that procures courses from the departments that employ researchers and teachers.

On top of these layers are the eight Areas of Advance $(\mathrm{AoA})^{8}-$ an organisational structure introduced in 2010 with the vision to "match [CUT] scientific excellence to global challenges" and the mission "to create a unique integration of the KT" in thematic areas [CUT, 2011, p. 4]. The AoA vice president holds the formal responsibility of implementing the KT. The AoA were the result of a government initiative to strengthen strategic research areas that provided AoA with significant funding. A national evaluation of the initiative praised the AoA and recommended increased funds [Swedish Research Council, 2015]. Lately, rhetorical KT references in relation to the AoA have faded (C6) and the AoA have developed into platforms for third mission activities and cross-cutting research targeting scientific excellence (C1, [CUT, 2016]).

The AoA is a unique initiative but a somewhat natural trajectory for an ambitious university with strong management and industrial traditions. Over the course of thelast few decades, CUT has strived to transform itself into an entrepreneurial university and has established innovative structures such as a venture capital firm, a seed financing company and an entrepreneurship school [Jacob et al., 2003; Fogelberg, Lundquist, 2012]. This has successfully integrated innovative research, entrepreneurial education and action-based training [Jacob et al., 2003]. However, these structures emerged as ad-hoc experiments without clear guidelines under diverse legal structures and were steered by strong individuals. This created opacity and fragmentation [Jacob et al., 2003] that increased with additional, often government-induced, third mission initiatives. One example is the innovation office, a service function installed in 2010 targeting research utilisation. Despite revisions during the last decade, the sense of opacity somewhat remains. Thus, the current vice president of utilisation has a strong focus on integration and coordination (C6).

Despite CUT's AoA and innovation support structure, management schemes seldom target KT integration. Recently (2016), CUT introduced a faculty fund allocation system and guidelines for staff appointments that account for the three core tasks. However, task integration is not a priority and some researchers and deans argue that staff appointments will become less flexible and that the emphasis is on traditional academic excellence at the expense of societal engagement (C2, C3). Relevant management schemes targeting the third mission also have appeared within individual departments. Examples are the appointments of vice deans responsible for the research utilisation, the development of long-term strategies and key performance indicators as well as employee support and encouragement through salary negotiations and work procedures ([Hillemyr et al., 2015], C2).

\section{Observed challenges in realising knowledge triangle links}

Although CUT's AoA and innovation efforts have been advantageous, significant difficulties related to realising the KT remain. Firstly, the division of roles between the departments, the infrastructure for innovation and the AoA is unclear. The AoA have responsibility regarding the KT, but the departments hold the human resources and are responsible for core tasks. KT connections created by AoA appear to be rare $(\mathrm{C} 1, \mathrm{C} 7)$. Rather, connections mainly emerge due to intra- departmental research $(\mathrm{C} 3, \mathrm{C} 1)$. As a researcher put it:

"We had developed our connections [before the AoA]. We had the applications, the international cooperation, the government relations, etc. [...] For us, [AoA] has been more of a hassle and created ambiguity [...] it's getting so much more complex, and you do not know what to expect from whom anymore." (C7)

Secondly, tensions stem from the perceived distance between management and researchers. Some faculty think that that management's goals are over-ambitious and inaccurate:

"I think management is over-ambitious [...] management is trying to steer things that they have little influence over, and limited information about." (C7)

"The management is somewhat inconsistent [...]one moment we should focus on innovation, the next we should be excellent [...] but we know our business, it is through [the faculty] that the knowledge triangle is realised." (C3)

\footnotetext{
${ }^{8}$ The areas are Energy, Materials Science, Nanoscience and Nanotechnology, Production, Transport, Life Science, Information and Communication Technology and Built Environment.
} 
Thirdly, although tension between research and innovation at CUT have been perceived as minor [Fogelberg, Lundquist, 2012], there is still some distance between support structures and real needs (C6). While some faculty utilise the support to act entrepreneurially, others think that the structures signal a too narrow a view on utilisation (C7). Also, there is some divergence concerning the focus on excellence:

"I notice an augmented pressure to strive for academic excellence, but there are significant trade-offs [...] I am concerned because this increased pressure may potentially hinder societal engagement [...] and the development of new research venues." (C3)

There are however also concerns about the ability of academia to conduct unbiased and curiosity-driven research in the light of third mission ambitions (C7).

Fourthly, significant tensions concern education:

"The education task has at times been taken hostage by innovation and research players [...] that have influenced the content of education programmes, dominantly based on perspectives from research and innovation that aren't necessarily in line with those of education [...] Strengthening the connection between education and the third mission is not about matching students to the direct needs of beneficiaries or introducing individual elements where students are utilised to reach [innovation goals]. Instead, [strengthening the connection] should be about producing students who can formulate problems that address societal challenges and critically observe society to push societal development in the right direction." (C5)

The organisation for education and the AoAs have both worked with integrating societal engagement in education, but in a rather uncoordinated and unsuccessful way (C1, C5, C2). However, interviewees are sceptical towards a stronger integration of education into the AoA due to the risk of increased complexity. Finally, tensions have emerged between faculty or department initiatives, external initiatives, and university-wide strategic schemes - mainly due to overlapping missions, resources and mandates. For example, the innovation office was created as a government induced add-on organisation. Although their activities have been significant for third mission developments, they have not yet been successfully integrated $(\mathrm{C} 1, \mathrm{C} 6)$.

\section{Malmö University}

Malmö University (MU) was founded in 1998 as a state accredited university college, granting it powers to award undergraduate and master's degrees and with a restricted remit for the award of doctoral degrees. MU is the ninth largest higher educational institution in Sweden with five different faculties, providing over 100 programmes of study and 350 courses to well over 20,000 students and almost 200 graduate students. In 2016, it was announced that MU would become an accredited "university" in 2018, which, inter alia, means that it will be empowered to award doctoral degrees without restrictions, as well as receive increased state subsidies for research.

\section{Informal institutions}

Interviews contained few direct references to the $\mathrm{KT}$ itself, but societal interaction was a recurrent theme in the self-understanding of MU. One interviewee (M1) described MU as "quick and flexible", keen to engage with societal challenges such as migration and inequality. Societal engagement thus emerged as a core value for Malmö, including "social innovation" in a very broad sense: "it's about processes, not things - meetings, feelings, experiences" (M1). This attitude helps to cement and embed KT principles within the university, and students and faculty are inspired by interactive attitudes and opportunities. Hence, the connections between education, research and innovation are viewed as an integral and attitudinal part of all activities at the university. The approach is more cultural than formalised:

"I don't think in a triangle way - I try to look at the strategy and the vision that we have - dynamic system thinking is more useful here. A triangle model is perhaps not so helpful." (M2)

In line with the broad understanding of the university's role, its representatives articulated quite eclectic perspectives on innovation. One of the interviewees (M3) emphasised a belief that there should be a variety of forms of innovation rather than merely commercial applications. Involving external parties in the early stages of research processes is seen as having an impact on what "knowledge" is for MU and is a valued form of interaction.

Achieving this is not seen primarily as a matter of drawing on experiences developed elsewhere; important knowledge on societal collaboration resides within the university itself, and there is a need to generalise these experiences beyond the specificities of these individual undertakings (M1). One way in which Malmö could better structure their KT activities is by generalising the experiences made inside the university (M2). More research could be done, for example, to evaluate collaborative projects in a way that forms a subject for research in itself. Another way to enhance the structure of the KT is to move away 
from spontaneous interactions with societal stakeholders to a more focussed and conscientious model, where the rich and dense societal networks of MU could be translated into research strongholds:

"People are very committed to solving societal challenges at $M U$, it is in their mindset. People already have the drive, although they need to develop awareness about relating work to research in a more focused way. Research at MU needs to be boosted via these collaborative projects." (M2)

Regarding the topics for societal engagement, one interviewee stressed that social sustainability could form a particularly good platform, relating strongly to the KT as well as to many different societal challenges, while still putting the university at the centre (M4). This approach has also been used in forming alliances within different calls based on principles of "grand challenges", for instance within the European Union Horizon 2020 programme (M1).

As a very recently established university college, MU has been more heavily focused on teaching, particularly professional education, and practical, socially contextualised outcomes. MU's identity is shaped by comparisons with the older universities of Sweden, which tend to be research-focussed with a broader educational profile; in contrast, $\mathrm{MU}$ is focussed on professional training and expectations emerging from a societal context.

"We are more heavily focused on education, particularly professional education. As a relatively recently established university, we put an emphasis on these more practical, socially contextualised aspects." (M4)

This is demonstrated also in the university's recruitment patterns. As an example, one third of MU doctoral candidates are employed outside of academia, most often working on their doctorate on a part-time basis. This brings in a lot of outside influence, giving the university a clear "imprint" outside in the world beyond its doors and providing opportunities for obtaining commissioned research contracts (M3).

\section{Formal institutions}

MU leadership brings together different backgrounds that combine many years of public organisational experience, private sector management and experience in running long-term collaboration activities with societal actors (M1, M2, M4). The MU leadership see the combination of these sectors as a major driver of quality in education and research. Societal challenges form the core mission for the entire university, rather than being peripheral add-on activities (M2, M4). Even though models like the KT are seen as somewhat too rigid and unimaginative to function as organisational blueprints, they serve as mementoes and ideals stressing the virtues of aligning the three missions. There are also tangible organisational signals for the significance of societal connectivity, for instance, the university functions as a national hub for social innovation. This is an important profile for the university and is seen as a way to attract potential external funding and collaborators (M2, M4).

There is much innovative work being done by staff and students that senior management would like to harness, in particular by evaluating their collaboration activities in more detail and therefore providing opportunities for further research projects (M2, M4). As societal interaction is such a strength at Malmö, "there is a huge communication task ahead" (M4) concerning how to raise the profile of these kinds of collaborative activities with civic society, explaining what they do and how they are beneficial. One example is MU's active engagement in crime prevention research, a key issue for the long-term viability of Malmö as a city (M1).

MU continues to integrate the KT elements predominantly through its overall value-based approach to innovation and inclusivity within its internal systems for recruitment and promotion. Its own merit system for employment takes into account experience with innovation and collaborative work (M2). The university has a model for the distribution of faculty research funding based on an average from the last three years' external funding that does not discriminate between different sources (e.g. EU, regional or corporate). This becomes an incentive for making contacts with outside partners. Another example is trainee teachers working in the local community who are being used as "change agents" by creating "innovation hubs" for education, who subsequently becomes links that create research opportunities (M4).

Senior management would also like to create a common space where faculty, staff and students can "get out of their daily routines in life and work" and become more open to communication with external partners. MU has also developed value-based leadership at the Anna Lindh Academy ${ }^{9}$ with a special focus on large public and private organisations (M2, M4).

A core aim at MU is to extend research into society and bring society into research. The principles of embedding knowledge flow between actors is "not really top-down" and is "built-into" the core activities of education and research (M3). Often MU works with the NGO sector and this kind of cooperation is embedded in the university, becoming the "regular way of thinking and acting" (M3). Collaborative efforts are a serious added dimension to teaching and research, and experience with collaborative activities is now seen as an important criterion during the recruitment process.

\footnotetext{
9 "Anna Lindh Academy was founded with the aim to contribute to a new generation of value-driven leaders who promote human rights and democracy both in Sweden and internationally". (http://annalindhacademy.se/om-anna-lindh-academy)
} 


\section{Observed challenges in realising knowledge triangle links}

The many societal interaction initiatives taking place at MU are being used to strengthen the university's research base which is currently scattered: some areas are well-endowed and resourceful whereas others are nascent or non-discernible. Much depends on the effectiveness of measures adopted at various levels, including national policy: Senior management feels that better opportunities for interaction and innovation projects are needed and that more than just economic goals should guide the steering mechanism of research funding at the national level (M2, M4). This may, however, be partially alleviated by MU's elevation to full university status in 2018.

Hence, MU straddles two positions: wanting to expand its research basis (which would necessitate an adherence to the current model of competitive funding) but also securing a protected and growing space for interactive activities, which would cater to a broader constituency of interests. According to MU's leadership, social innovation is MU's niche in the Swedish university system. It has different needs from other forms of innovation, and specific tools, goals, financing and structures are required to serve this purpose (M2, M3, M4).

Sweden faces structural problems, such as funding for higher education, particularly in terms of facilitating societal engagement. According to MU's leadership, all interested parties must come together to solve societal problems, however, currently there are not enough incentives as funding is lacking. Also, the feeling is that the current funding scheme favours the funding of more traditional universities for structural and political reasons (M2). In addition, at MU $80 \%$ of the revenue is dedicated to education and $20 \%$ to research, so there is a great imbalance and limited resources to build a foundation for doctoral education and multi-faceted research environments. Thus, MU's leadership sees the integration of funding for education and research as necessary to better align the various tasks of the university.

\section{Discussion on the paper's findings}

The previous section revealed the approaches to orchestrating the KT at three universities. CUT is purposefully orchestrating the KT through a matrix scheme. Difficulties have arisen as the new structure complicates resource flows and governance, both vertically between organisational levels, as well as horizontally between the three KT components. LU has a weak steering centre and considerable variation between its different constituent parts. The organisation of KT activities reflects these differences, where a recently adopted top-down approach co-exists rather uneasily with bottom-up activities, and where some faculties have profound and well-elaborated models, others have only minimal experience. MU has predominantly been focused on education. As a result of limited research funding, the administration has been forced to find innovative ways of seeking external funding, primarily through interactions with the local community. However, contradictions exist between current structures for research funding in Sweden and the principles of KT integration that MU aims to realise.

Combined, the cases leave us with four key observations on the manifestation of the KT at universities. Firstly, there are contradicting views within the universities related to the third mission and the KT. This observation is in line with those of Sjoer et al. [Sjoer et al., 2016] who identify a great diversity in perceptions that actors have of their tasks, and that not all actors adhere to KT principles. While this may be expected at a broad and decentralised university such as LU, or a young and evolving university as MU, the observation of contradicting views at a management-driven university such as CUT is less expected. When comparing the experiences, funding patterns and mandates of interviewees with their own views, we find indications of how the fragmented Swedish higher education and research system contributes to this diversity. The separated funding streams (for the three tasks, and for research in particular) each channel divergent views on the third mission and task integration, which strongly influence concerned actors at the universities. A clear consequence observed in all three cases is that innovation is conducted on an ad hoc basis, either enabled by different funding actors or driven by individual initiatives. The result is a fragmentation between the various tasks and a lack of clarity about the benefits of strengthened integration.

Secondly, it is clear that education has fallen into second place and that the focus on research excellence and attaining research financing has overshadowed the incentives of an integrated KT. These findings are in line with Geschwind and Broström [Geschwind, Broström, 2015] who found signs of a growing division of labour between teaching and research at Swedish universities. However, the task separation and research dominance is less clear at MU. Dominated by educational activities and adhering to a civic context, MU does not fall in line with traditional academic expectations in the same way as CUT and LU do.

Thirdly, the on-going macro level process of professionalisation and integration of the third mission has been challenged by the drive for research excellence. At LU, challenges have varied with the diverse prevailing conditions within different faculties and groups, while at CUT the conflicts regarding goals between research and the third mission are clearer. MU has provided good examples of KT principles in practice by using societal interactions to maximise investment in research, but still faces difficulties dealing with existing research funding structures. For instance, MU exemplifies how creative approaches 
to KT integration through societal engagement can be underfunded due to a preoccupation by funding bodies with industrial collaboration over civic engagement, or when the societal impact is disregarded altogether.

Finally, the universities have used their increased autonomy in different ways with diverse consequences for orchestrating KT principles. Following its proactive management tradition of responding to external expectations, CUT has continued on the road of creating structures and defining processes by mediating visions of KT integration through the new organisation of AoA. However, vertical contradictions have emerged due to the unclear distribution of mandates between overlapping structures, and because incentives for researchers to strengthen KT principles at the individual level are not in line with political ambitions at the institutional and national levels. LU has mainly redistributed the increased autonomy to the faculties by increasing their mandate. This has led to a more dispersed orchestration where KT initiatives must emerge in a bottom-up manner to gain legitimacy. The result is a federation of faculties that are not directed in a uniform way. Consequently, the decentralised (and autonomous) faculties further exacerbate the aforementioned division between the KT elements due to the pursuit of excellence. MU is more adaptable given its youth and modest size, but is however limited by its rather small resources. The result is promising visions combined with the potential for being an evolving university species, but a lack of strength for execution.

\section{Conclusions and implications}

This paper deals with how universities blend their key tasks. We set out to study how KT principles are manifested in the organisation and strategies of different types of universities. The exploratory approach has provided us with rich descriptions from three universities. We observe great diversity in the way in which the principles of KT (bringing together education, research and innovation) are orchestrated at the universities, both in terms of informal institutions such as interpretations and attitudes, and in terms of formal institutions such as articulated strategies and incentive schemes. On the macro level, the KT remains a policy priority and living concept, yet task integration is increasingly expected to be arranged by the universities themselves. Our study reveals the limited ambitions from university management teams to forge new combinations of remits. This in turn mirrors the structure of policymaking in Sweden, where the areas of research, education and innovation have been compartmentalised in terms of funding and governance. As this structure trickles down to the individual and group level, we observe that the articulation of tasks is weak. What we do find is that some individuals take on the task of aligning the three missions despite the obstacles, and thus serve as role models and KT exemplars. We also observe the difficulties as the responsibilities of operationalising the KT often fall upon individuals who sometimes lack the mandate and resources to create enabling conditions and tackle divergent expectations. With these findings, we make a significant empirical contribution to the understudied phenomenon of the KT. To sum up, our major empirical observation is that there is a misalignment between the political goal of implementing the KT and the actual policy mechanisms of the key components. Despite the ambition to reduce the political regulation of universities, the resource flows (and concomitant evaluation and assessment criteria) foster a compartmentalised strategy.

These observations offer implications for policymakers and universities. A key group of actions concern supporting the development of the knowledge needed to fill aforementioned gaps. If future research indicates that we are in fact to create balanced and mutually beneficial links between research, education and innovation within a single university, we need to create a reliable, sustainable and reasonably adaptable (allowing for variation) operational model of the KT, to serve as a flexible starting point for the articulation of the different tasks. Our results suggest that this would require extensive and profound changes in the Swedish academic system. The increased resources and autonomy that the sector has experienced so far has not proven sufficient incentives to foster better ties; indeed, it could be argued that they were better aligned when state regulation was more pronounced. Initiatives for change cannot only emerge through external funders' initiatives and programs, but must also stem from the universities themselves. This would require an academic leadership that, together with the collegiate, could formulate and implement the ambitious goals and strategies required to realise a truly productive KT.

These findings also raise questions for further research. Firstly, a significant but methodologically necessary limitation is that we see the KT linkages as a given in the setting of contemporary universities, form and take them for granted as our point of departure. Consequently, what remains is the question of the actual cost effectiveness of the division of labour vis-à-vis the advantages stemming from the integration. Secondly, it is unclear whether the university is the most suitable level at which the KT should be orchestrated. 


\section{References}

Aghion P., Dewatripont M., Hoxby C., Mas-Colell A., Sapir A. (2008) Higher Aspirations: An Agenda for Reforming European Universities (Bruegel blueprint 5, July 2008), Brussels: Bruegel.

Benner M. (2013) Nordiska universitet i jakt på världsklass - en jämförelse mellan två universitet $i$ Danmark och Sverige [Nordic universities in search of world class - a comparison between the two universities in Denmark and Sweden] (Working paper/PM 2013:20), Östersund: Tillväxtanalys (in Swedish).

Benner M., Sörlin S. (2015) Samverkansuppgiften i ett historiskt och institutionellt perspektiv [Collaboration tasks in a historical and institutional perspective], Stockholm: Vinnova (in Swedish).

Bienenstock A., Schwaag-Serger S., Benner M., Lidgård A. (2014) Utbildning, forskning, samverkan. Vad kan svenska universitet lära av Stanford och Berkeley [Education, research, collaboration. What can Swedish universities learn from Stanford and Berkeley], Stockholm: SNS Förlag (in Swedish).

Bozeman B., Boardman C. (2014) Research Collaboration and Team Science: A State-of-the-Art Review and Agenda, Heidelberg; New York; Dordrecht; London: Springer International Publishing.

Buenstorf G. (2006) Is Academic Entrepreneurship Good or Bad for Science?: Empirical Evidence from the Max Planck Society, Jena (Germany): Max Planck Institiute of Economics.

Carlsson H., Kettis Å., Söderholm A. (2014) Research Quality and the Role of the University Leadership (Report commissioned by the Association of Swedish Higher Education (SUHF)/Experts' Committee on Quality), Stockholm: Elanders Sverige AB.

CUT (2011) Areas of Advance (Bulletin no 1, November), Gothenburg (Sweden): Chalmers University of Technology. CUT (2016) Årsredovisning 2015 [Annual Report 2015], Gothenburg (Sweden): Chalmers University of Technology (in Swedish).

Clark B.R. (1997) The modern integration of research activities with teaching and learning. Journal of Higher Education, vol. 68, no 3, pp. 241-255.

Clark B.R. (1998) Creating entrepreneurial universities: Organizational pathways of transformation, Bingley (UK): Emerald Group Publishing.

Colbeck C.L. (1998) Merging in a Seamless Blend: How Faculty Integrate Teaching and Research. The Journal of Higher Education, vol. 69, no 6, pp. 647-671.

D'Este P., Perkmann M. (2011) Why do academics engage with industry? The entrepreneurial university and individual motivations. The Journal of Technology Transfer, vol. 36, no 3, pp. 316-339.

European Commission (2005) Mobilising the brainpower of Europe: Enabling universities to make their full contribution to the Lisbon strategy (COM(2005) 152 final), Brussels: European Comission.

Eriksson L., Heyman U. (2014) Resurser för utbildning och forskning [Resources for Education and Research] (Dnr 14/014SUHF, April 2014), Stockholm: Sveriges universitets- och högskoleförbund (SUHF) (in Swedish).

Etzkowitz H., Leydesdorff L. (2000) The Dynamics of Innovation: From National Systems and "Mode 2" to a Triple Helix of University-Industry-Government Relations. Research Policy, vol. 29, no 2, pp. 109-123.

Fagerberg J., Verspagen B. (2009) Innovation studies - The emerging structure of a new scientific field. Research Policy, vol. 38, no 2, pp. 218-233.

Fogelberg H., Lundqvist M.A. (2012) Integration of academic and entrepreneurial roles: The case of nanotechnology research at Chalmers University of Technology. Science and Public Policy, vol. 40, no 1, pp. 127-139. DOI: 10.1093/ scipol/scs074.

Geschwind L., Broström A. (2015) Managing the teaching-research nexus: Ideals and practice in research-oriented universities. Higher Education Research and Development, vol. 34, no 1, pp. 60-73.

Gibbons M., Limoges C., Nowotny H. (1994) New Production of Knowledge, Thousand Oaks, CA: Sage Publications.

Goosens M., Sjoer E. (2012) Expanding the concept of Knowledge Triangle to foster the working of the Triple Helix Model. Paper presented at the IACEE World Conference on CEE, UPV, Valencia, May 16-19, 2012.

Government of Sweden (2016) Trygghet och attraktivitet - en forskarkarriär för framtiden, Stockholm: Elanders Sverige AB. Available at: http://www.regeringen.se/contentassets/e43bb9e3a614499e807857372bf19d4c/trygghetoch-attraktivitet--en-forskarkarriar-for-framtiden-sou-2016_29.pdf, accessed 06.04.2017 (in Swedish).

Gulbrandsen M., Smeby J.-C. (2005) Industry funding and university professors' research performance. Research Policy, vol. 34, no 6, pp. 932-950.

Hillemyr A., Hörstedt F., Lövsund P. (2015) Implementation of an organisational model to stimulate interaction between academia and industry. Paper presented at the University-Industry Interaction Conference (UIIN), Berlin, June 24-26, 2015.

Holmberg J. (2015) Speech by Vice President of Sustainability John Holmberg during workshop on innovation and sustainability transitions, organised by Chalmers Initiative for Innovation and Sustainability Transitions (CIIST), Gothenburg, November 17.

Holmén M., Ljungberg D. (2015) The teaching and societal services nexus: Academics' experiences in three disciplines. Teaching in Higher Education, vol. 20, no 2, pp. 208-220.

Holmén M., Ljungberg D. (2016) Förnyelsens källor. Sveriges entrepreneuriella ekosystem (eds. M. McKelvey, O. Zaring), Stockholm: Esbri, pp. 150-163.

Jacob M. (2015) RIO Country Report Sweden 2014 (Joint Research Centre Institute for Prospective Technological Studies, Science and Policy Report, EUR 27306 EN), Brussels: European Commission.

Jacob M., Lundqvist M., Hellsmark H. (2003) Entrepreneurial transformations in the Swedish University system: The case of Chalmers University of Technology. Research Policy, vol. 32, no 9, pp. 1555-1568.

Jacobsson S., Perez Vico E. (2010) Towards a systemic framework for capturing and explaining the effects of academic R\&D. Technology Analysis and Strategic Management, vol. 22, no 7, pp. 765-787.

Laredo P. (2007) Revisiting the third mission of universities: Toward a renewed categorization of university activities? Higher Education Policy, vol. 20, no 4, pp. 441-456. 
Larsen M.T. (2011) The implications of academic enterprise for public science: An overview of the empirical evidence. Research Policy, vol. 40, no 1, pp. 6-19.

Lund University (2012) Strategic Plan Lund University 2012-2016, Lund (Sweden): Lund University.

Lund University (2015) Resultat av översyn av verksamheterna inom sektionen Forskning, samverkan och innovation (Rapport från utredningen 2015-10-15, Dnr STYR 2015/511) [Results of review of operations in Research section, interaction and innovation (Research report 2015-10-15, Dnr STYR 2015/511], Lund (Sweden): Lund University (in Swedish).

Maassen P., Stensaker B. (2011) The knowledge triangle, European higher education policy logics and policy implications. Higher Education, vol. 61, no 6, pp. 757-769.

Mansfield E. (1998) Academic research and industrial innovation: An update of empirical findings. Research Policy, vol. 26, no 7, pp. 773-776.

Markkula M. (2013) The knowledge triangle: Renewing the university culture. The Knowledge Triangle: Re-inventing the Future (eds. P. Lappalainen, M. Markkula), Brussels: European Society for Engineering Education (SEFI).

Marsh H.W., Hattie J. (2002) The relation between research productivity and teaching effectiveness: Complementary, antagonistic, or independent constructs? The Journal of Higher Education, vol. 73, no 5, pp. 603-641.

Martin B.R., Etzkowitz H. (2000) The Origin and Evolution of the University Species. VEST, no 3-4, pp. 7-32.

North D. (1990) Institutions, Institutional Change and Economic Performance, Cambridge: Cambridge University Press.

OECD (2016a) Emerging Policy Issues in the Knowledge Triangle (DSTI/STP(2016)4), Paris: OECD.

OECD (2016b) OECD Reviews of Innovation Policy: Sweden 2016, Paris. OECD. Available at: http://dx.doi. org/10.1787/9789264250000-en, accessed 23.02.2017.

Perkmann M., Walsh K. (2007) University-industry relationships and open innovation: Towards a research agenda. International Journal of Management Reviews, vol. 9, no 4, pp. 259-280.

Perkmann M., Tartari V., McKelvey M., Autio E., Broström A., D’Este P., Fini R., Geuna A., Grimaldi R., Hughes A., Krabel S., Kitson M., Llerena P., Lissoni F., Salter A., Sobrero M. (2013) Academic engagement and commercialisation: A review of the literature on university-industry relations. Research Policy, vol. 42, no 2, pp. 423-442.

Perkmann M., King Z., Pavelin S. (2011) Engaging excellence? Effects of faculty quality on university engagement with industry. Research Policy, vol. 40, no 4, pp. 539-552.

Pinheiro R., Geschwind L., Aarrevaara T. (2014) Nested tensions and interwoven dilemmas in higher education: The view from the Nordic countries. Cambridge Journal of Regions, Economy and Society, vol. 7, no 2, pp. 233-250.

Pinheiro R., Langa P.V., Pausits A. (2015) One and two equals three? The third mission of higher education institutions. European Journal of Higher Education, vol. 5, no 3, pp. 233-249.

Robertson J., Bond C.H. (2001) Experiences of the Relation between Teaching and Research: What do Academics Value? Higher Education Research and Development, vol. 20, no 1, pp. 5-19.

Scott A., Steyn G., Geuna A., Brusoni S., Steinmueller E. (2001) The economic returns to basic research and the benefits of university-industry relationships. A literature review and update of findings (Report for the Office of Science and Technology), Brighton (UK): University of Sussex.

Scott W.R. (2014) Institutions and organizations. Ideas, interests, and identities (4 ${ }^{\text {th }}$ ed.), Thousand Oaks, CA: Sage Publications.

Sjoer E., Nørgaard B., Goossens M. (2016) From concept to reality in implementing the Knowledge Triangle. European Journal of Engineering Education, vol. 41, no 3, pp. 353-368.

Slaughter S., Campbell T., Holleman M., Morgan E. (2002) The "Traffic" in Graduate Students: Graduate Students as Tokens of Exchange between Academe and Industry. Science, Technology \& Human Values, vol. 27, no 2, pp. 282-312.

Sonnenwald D.H. (2007) Scientific collaboration. Annual Review of Information Science and Technology, vol. 41, no 1, pp. 643-681.

Stensaker B., Benner M. (2013) Doomed to be Entrepreneurial: External and Internal Factors Conditioning the Strategic Development of 'New' Universities. Minerva: A Review of Science, Learning and Policy, vol. 51, no 4, pp. 399-416.

Swedish Higher Education Authority (2015) Universitet och högskolor: Årsrapport 2015 [Universities and colleges: Annual Report](Report number 2015:8, June 2015), Stockholm: Universitetskanslersämbetet (in Swedish).

Swedish Research Council (2015) Evaluation of the Strategic Research Area Initiative 2010-2014, Stockholm: Swedish Research Council. ISBN: 978-91-7307-282-3.

Wigren-Kristoferson C., Gabrielsson J., Kitagawa F. (2011) Mind the gap and bridge the gap: Research excellence and diffusion of academic knowledge in Sweden. Science and Public Policy, vol. 38, no 6, pp. 481-492. 